\title{
NURSING STUDENT'S PERCEPTION REGARDING HEALTH PROMOTION AND HEALTH EDUCATION
}

\author{
*Fazal Rahman \\ *** Muhammad Hussain \\ **** Muhammad Afzal \\ *****Syed Amir Gillani
}

\section{Abstract}

Background: Promoting health is a key component of nursing practice- By helping nurses change individuals, society and healthcare system by promoting the health of individuals, families, communities and populations.

Purpose: The aim of the study is to show the understanding of nursing student's perception regarding health education and health promotion.

Study design: Cross sectional study.

Setting: Lahore School of Nursing, the University of Lahore.

Duration: 4 months from September 2019 to December 2019.

Methodology: this study was done on 135 nursing students selected through convenient sampling method from Lahore School of Nursing, the University of Lahore. Data was collected by modified questionnaire adopted from (Halcomb, 2010) to understand the perception of nursing students regarding health promotion and health education.

Results: This study finds out that $90 \% \mathrm{n}=122$ participants have positive perception regarding health promotion and health education. Although there were some signs that nursing students were introduced to the concept of health promotion as a socio-ecological strategy that integrates changes in the economy, policy, organization and climate. This socio-ecological approach was not viewed by the majority of student nurses as having a role modeling faculty or nurses.

Conclusion: students nurses to be recognized as future high quality health promoters, collaborates with wellbeing advancement leaders, and effectively teach nursing education. There is a need to made changes in the nursing curriculum to reflect appropriate and accurate health promotion concepts and performed health promoting behaviours which have strong impact on individual health.

Keywords: Health Education, Health Promotion, Nursing Student, Perception.

\subsection{Introduction}

Promoting health "is defined as any arranged combination of education, political, natural, disciplinary, or organizational implements that encourage lifestyle and living environment and that influence people, groups and communities" (Hosseinpoor, Bergen, \& Schlotheuber, 2015).

Health education is an event aimed at informing people about the essence of health/disease and the risks associated with the individual's lifestyle behaviours and actions. Health education seeks to accelerate the process of behaviour change by directly influencing an individual's values, beliefs, and attitudes, where the individual is believed to be particularly at risk or to have a disease, illness or disability (Gilbert, Sawyer, \& McNeill, 2014).

The words promoting and education health have been misused in the nursing literature and in practice. Health education and health promotion are, in fact, separate activities. The concept of wellbeing advancement, which centers on social and natural determinants and partner participation in health, includes the narrow view of health education (Woods, Cashin, \& Stockhausen, 2016).

It is the responsibility of nurses' educators to spread nursing knowledge. The future undergraduate nursing students will be impacted by standardized nursing education systems as well as individuals working in the workplace, healthcare staff, peers and media, emotions and beliefs (Patterson et al., 2017). Nursing educators need to have an understanding of wellbeing, wellbeing advancement, and wellbeing instruction in order to be part of nursing, not just illness and disease prevention (Bastable, 2017).

It is the responsibility of health professionals to improve health at the person, community and economic levels. Nurses have the opportunity to contribute to the field of wellbeing development and health education as the biggest group of healthcare experts. Health promotion and health education is based on global architecture. Wherever they are organized and experienced, they want to 
establish a common principle between healthcare professionals and their setting. To date, most nursing education focuses on the European or North American context in this area (Whitehead et al., 2015). This study presents a unique perspective of nursing students about health promotion and health education in Pakistan.

\section{Problem Statement}

Various studies have been conducted previously in the United States, the United Kingdom, Canada, New Zealand and many other countries on perception about health promotion and health education; In Pakistan, there is little work in terms of advancing wellbeing and understanding wellbeing instruction in nursing students. Both the policies and practices of health education and health promotion were ignored in a country like Pakistan, in which communication costs one of the lowest per capita expenditure on health and the death rate due to communicable diseases is high, measures for prevention and health promotion practices are important in reducing the burden of diseases (Qidwai, 2016).

\section{Research Question}

The study was guided by the following research questions:

1. How do nursing students define health?
2. Can nursing students explain the difference between health education and health promotion?

3. What have nursing students been exposed to within their curriculum regarding health promotion?

4. What health promoting behaviours are nursing faculty role modelings's as perceived by nursing students?

5. What is the role of the nurse in implementing health promotion as perceived by nursing students?

\section{Significance}

Health education and health promotion is an important topic because health promotion improves quality of life for all people and health education provides information about physical, mental, social and spiritual health. The main focus of this study is primarily based on nursing students. Current study will create an insight of nursing students' perception about health promotion and health education as it is an important role of nurse. The finding of this study would facilitate students to have an understanding about role of nurse in health promotion. This study will open the door for other researcher to conduct study on evaluation of nursing students' perception about role of nurse in health promotion and how the concept of health promotion is presented in nursing curriculum.

\section{Conceptual Framework}

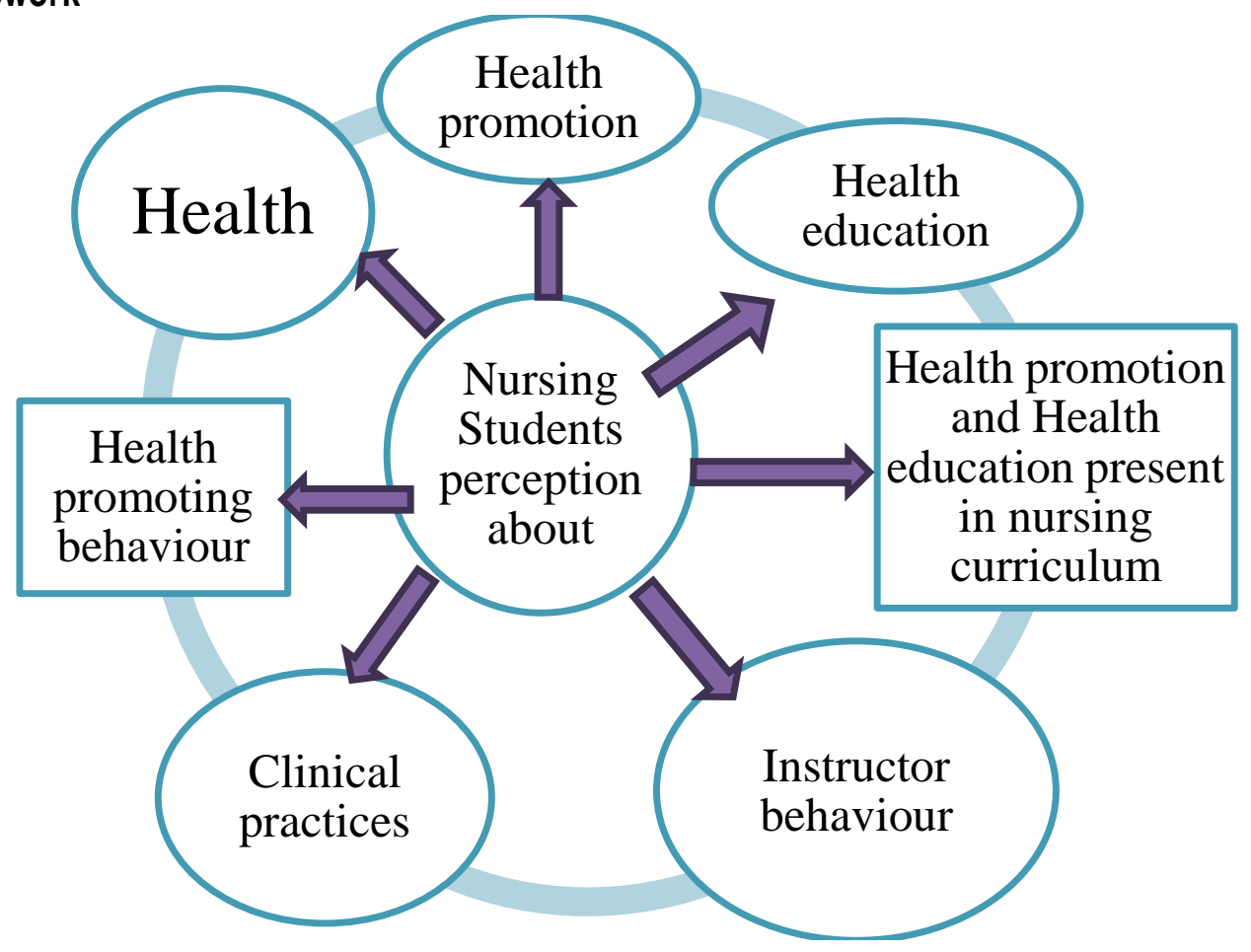




\subsection{Materials and Methods}

Study Design: Descriptive cross sectional study design was used in this study.

Study Setting: This study was conducted in Lahore School of Nursing, The University of Lahore.

Target Population: The population of this study was nursing students. The Lahore School Nursing students of Four-Year Bachelor of Science in nursing BSN degree program and BSN (Post RN) will be the population of this research study. Total population size of nursing students of BSN and BSN (Post RN) students are 205 and sample size of this study is 135 .

Sample Size: Sample size for this study was calculated by using slovin's formula:

$$
\mathrm{n}=\mathrm{N} / 1+(\mathrm{N})(\mathrm{e}) 2
$$

Inclusion Criteria: The study participants were include male and female students' age 18-44 years nursing students of Lahore School of Nursing registered in generic Bachelor of Science in nursing BSN and BSN post RN nursing. Study participants include students that give data conveniently. Those students was included who are full time participants of class, enrolled their subjects present students and those willing to participate in this study.

Exclusion Criteria: The students that not want to participate in study, Students that were absent from class and freeze their semester, Students that not enrolled.

Time Framework: This study was carried out in duration of 4 month, from September 2019 to December 2019.

Research Tool: A developed questionnaire adopted from (Halcomb, 2010) was used to collect data from the study participants. During data collection permission was taken from class faculty and students. There given time and a free hand to complete it and return it.

\subsection{Result}

\section{Section 1:}

This section represents the distribution of participant by demographic characteristics. The data is summarized in terms of frequency and percentage.

\section{Table 1.1: Description of Demographic Characteristics}

\begin{tabular}{|c|c|c|c|}
\hline \multirow{2}{*}{ Characteristics } & Category & \multicolumn{2}{|c|}{ Respondents } \\
\cline { 2 - 4 } & & Frequency & Percent \\
\hline \multirow{2}{*}{ Gender } & Male & 25 & $\mathbf{1 8 . 5 \%}$ \\
\cline { 2 - 4 } & Female & 110 & $\mathbf{8 1 . 5 \%}$ \\
\hline Age (years) & $18-22$ & 52 & $\mathbf{3 8 . 5 \%}$ \\
\hline \multirow{2}{*}{ Religion } & $23-27$ & & $\mathbf{6 1 . 5 \%}$ \\
\hline \multirow{2}{*}{ Nursing program enrolled } & Muslim & 107 & $\mathbf{7 9 . 3 \%}$ \\
\hline \multirow{2}{*}{$\begin{array}{c}\text { Used a fundamental nursing } \\
\text { text book? }\end{array}$} & Christian & 28 & $\mathbf{6 5 . 9 \%}$ \\
\hline & Yaccalaureate & 89 & $\mathbf{3 4 . 1 \%}$ \\
\hline & Nost RN & 46 & $\mathbf{9 1 . 9}$ \\
\hline
\end{tabular}

The classification of Demographic characteristics of participants is shown in Table 01.

Gender of the participants involved in the study were male $\mathrm{n}=25(18.5 \%)$ and female $\mathrm{n}=110$ $(81.5 \%)$. The frequency of female is higher than male in this study. The majority of participants involved in this study were $\mathrm{n}=83(61.5 \%)$ belong to the age group 23-27 years and $n=52(38.5 \%)$ belong to the age group 18-22 years. participants involved in this study were $\mathrm{n}=107(79.26 \%)$ were Muslims, and $\mathrm{n}=28(20.74 \%)$ were Christian. $\mathrm{n}=$ $89(65.93 \%)$ participants were belong to baccalaureate program and $n=46(34.1 \%)$ belong to Post RN. that majority of student $\mathrm{n}=124$ 


\section{Section 2}

\section{Definition of health and factor related to health:}

\begin{tabular}{|c|c|c|c|}
\hline \multicolumn{4}{|l|}{ Table no 1.3} \\
\hline Questions ask about the word health. & & Agree & Disagree \\
\hline & $\mathbf{N}$ & $\%$ & $\%$ \\
\hline Health is a state of physical, social and mental well-being. & 135 & $86.7 \%$ & $13.3 \%$ \\
\hline Health is a resource for everyday living. & 135 & $60 \%$ & $40 \%$ \\
\hline $\begin{array}{l}\text { Health is a positive concept emphasizing social and personal } \\
\text { resources. }\end{array}$ & 135 & $65.9 \%$ & $34.1 \%$ \\
\hline $\begin{array}{l}\text { As long as an individual is without physical disease or illness } \\
\text { he/she has health. }\end{array}$ & 135 & $88.9 \%$ & $11.1 \%$ \\
\hline Individuals are responsible for their health. & 135 & $80.8 \%$ & $19.2 \%$ \\
\hline Social environments affect an individual's health behaviours. & 135 & $80.7 \%$ & $19.3 \%$ \\
\hline $\begin{array}{l}\text { Health is a process through which a person seeks equilibrium } \\
\text { that promotes stability and comfort. }\end{array}$ & 135 & $88.9 \%$ & $11.1 \%$ \\
\hline Only individuals without disease or illness have health. & 135 & $60 \%$ & $40 \%$ \\
\hline Health is the striving towards optimal functioning. & 135 & $72.6 \%$ & $27.4 \%$ \\
\hline The current health of an individual is directly related to: & & Agree & Disagree \\
\hline His or her personal choices. & 135 & $88.9 \%$ & $11.1 \%$ \\
\hline The community in which he/she lives. & 135 & $100 \%$ & $0.00 \%$ \\
\hline Both the community and his/her personal choices. & 135 & $88.9 \%$ & $11.1 \%$ \\
\hline
\end{tabular}

Table no 1.3 shows that the majority of the participants $88.9 \%$ agreed that process through which a person seeks equilibrium that promotes stability and comfort and individual without disease or illness, $86.7 \%$, agreed that health is a state of complete physical, social and mental wellbeing, However study population are less likely only $60 \%$ agreed to statement asked about health as a resource for everyday living. The overwhelming majority of participants $88.9 \%$ respond that current health of individual is related to both community in which and his/her personal choices. But the response was different when personal choices and community were separated into individual questions, $100 \%$ respond that health is related to community and $88.9 \%$ respond that it related to personal choices.

\section{Difference between concept of health promotion and health education:}

\section{Table no 1.4}

Questions ask about health education and health promotion.

Facilitating individuals with learning opportunities to improve health.

Concerned with giving

\begin{tabular}{|l|l|l|l|}
\hline HE & HP & Both & $\begin{array}{l}\text { Neither } \\
\%\end{array}$ \\
\hline$\%$ & $\%$ & $\%$ & 11.9 \\
\hline 51.1 & 22.2 & 14.8 & $\%$ \\
\hline 37.0 & 14.1 & 34.1 & 14.8 \\
\hline
\end{tabular}

information.

Motivating people to change health behaviours.

It assists individuals with the confidence needed to make changes in behaviour.

Assisting individuals in learning skills needed to change health behaviours.

Empowering communities to gain control over factors affecting their quality of life.

Influencing economic conditions affect health.

Influencing the physical environments which affect

\begin{tabular}{|c|c|c|c|}
\hline 61.5 & 38.5 & - & - \\
\hline 40.0 & 36.3 & 23.7 & - \\
\hline 36.3 & 63.7 & - & - \\
\hline 38.5 & 61.5 & - & - \\
\hline 14.1 & - & 63.7 & 22.2 \\
\hline- & - & 61.5 & 38.5 \\
\hline
\end{tabular}




\begin{tabular}{l|c|c|c|c|}
\hline health. & 28.9 & 45.9 & 25.2 & - \\
Making policies which affect health. & 14.1 & 14.8 & 48.9 & 22.2 \\
\hline Influencing social conditions affect health. & & & & \\
\hline
\end{tabular}

Table no 1.4 shows the nursing student perception about the difference between the concept of health promotion and health education, in which majority of participants $61.5 \%$ response to Health education in motivating people to change health behaviours, $38.5 \%$ respond that it is health promotion. Majority $63.7 \%$ participant's respond to health promotion that it is involved with assisting individuals in learning skills needed to change health behaviours, $36.3 \%$ respond that it is Health education. Influencing the physical environments which affect health overwhelming participants $63.7 \%$ respond to both.

\section{Concept of health education and health promotion presented in nursing curriculum:} Table no 1.5

\begin{tabular}{llllll}
\hline $\begin{array}{l}\text { Please identify in how many nursing classes the instructor } \\
\text { presented each concept }\end{array}$ & 0 & 1 & 2 & 3 & $4+$ \\
\cline { 2 - 5 } $\begin{array}{l}\text { Definition of Health Promotion (HP). } \\
\text { Definition of Health Education (HE). }\end{array}$ & 17.0 & 3.7 & 32.6 & 15.6 & 31.1 \\
\hline $\begin{array}{l}\text { HP empowers communities to gain control over factors } \\
\text { affecting quality of life. }\end{array}$ & 31.1 & 16.3 & 31.9 & 20.7 \\
$\begin{array}{l}\text { HP is involved with influencing economic } \\
\text { conditions which affect health }\end{array}$ & 10.4 & 7.4 & 37.8 & 31.9 & 12.6 \\
$\begin{array}{l}\text { HP is involved with influencing the physical environment } \\
\text { which affects health. }\end{array}$ & - & 16.3 & 32.6 & 3.7 & 47.4 \\
$\begin{array}{l}\text { HP is involved with making/changing policies which } \\
\text { affect health. }\end{array}$ & - & 16.3 & 3.7 & 64.4 & 15.6 \\
$\begin{array}{l}\text { HP is involved with influencing social conditions which } \\
\text { affect health. }\end{array}$ & 17.0 & 16.3 & 47.4 & 3.7 & 15.6 \\
\hline
\end{tabular}

Table no 1.5 shows that only $17.0 \%$ of the participants respond that definition of health promotion was never presented to them in nursing classes and $31.1 \%$ participant said that the definition of health education was presented zero time in nursing classes. When asked about the various concepts of health promotion and health education about $90 \%$ of concepts were presented at least twice. The concept that "HP is involved with influencing economic conditions which affect health" was never presented to $10.4 \%$ participants. The concept that is identified as least presented in nursing classes by nursing educator is HP is involved with influencing social conditions which affect health $17.0 \%$ see table 3.3 .

\section{Nursing students' health promoting behaviours upon completion on nursing program: Table no} 1.6

\begin{tabular}{llll}
\hline $\begin{array}{l}\text { Nursing students' health promoting behaviours upon completion } \\
\text { of nursing program. }\end{array}$ & $\begin{array}{l}\text { Will } \\
\text { performed }\end{array}$ & $\begin{array}{l}\text { Will } \\
\text { performed }\end{array}$ \\
\cline { 2 - 3 } & & $\mathbf{N}$ & be \\
Support a non-smoking policy for your place of employment. & 135 & $100.0 \%$ & $0.00 \%$ \\
\hline Support non-smoking law banning smoking in public places. & 135 & $72.6 \%$ & $27.4 \%$ \\
\hline Support non-smoking law areas involving children, & 135 & $58.6 \%$ & $41.4 \%$ \\
\hline Attend a national nursing conference. & 135 & $67.4 \%$ & $32.6 \%$ \\
\hline Offer smoking cessation education without a doctor's order. & 135 & $100.0 \%$ & $0.00 \%$ \\
\hline Offer child safety education to family members of clients. & 135 & $83 \%$ & $17 \%$ \\
\hline Assess a client's physical activity level. & 135 & $100.0 \%$ & $0.00 \%$ \\
\hline Assess a client's nutritional intake. & 135 & $100.0 \%$ & $0.00 \%$ \\
\hline Complete required continuing education hours. & 135 & $100.0 \%$ & $0.00 \%$ \\
\hline Assess a client's seat belt use. & 135 & $100.0 \%$ & $0.00 \%$ \\
\hline Assess the client for high risk behaviours, & 135 & $72.6 \%$ & $27.4 \%$
\end{tabular}




\begin{tabular}{|llll}
\hline Talk to clients about nutritional requirements. & 135 & $58.5 \%$ & $42.5 \%$ \\
\hline Talk to clients about recommendations for physical activities. & 135 & $67.4 \%$ & $32.6 \%$ \\
\hline Be involved in passing state laws affecting health. & 135 & $100.0 \%$ & $0.00 \%$ \\
\hline assisting your community in developing healthy environments & 135 & $72.0 \%$ & $27.0 \%$ \\
\hline Obtain yearly influenza vaccinations. & 135 & $100.0 \%$ & $0.00 \%$ \\
\hline Support changes for healthier selections & 135 & $100.0 \%$ & $0.00 \%$ \\
\hline Support the building of physical environments. & 135 & $100.0 \%$ & $0.00 \%$ \\
\hline Changing unhealthy lifestyle behaviours for clients. & 135 & $72.6 \%$ & $27.4 \%$ \\
\hline
\end{tabular}

Table no 1.6 results identified that majority of nursing students will perform specific health promoting activities such as talking to clients about recommendations for physical activities (67.5\%), assisting community in developing healthy environments $(72 \%)$, offering child safety classes to family members of clients (83\%), and Attending a national nursing conference $(67.4 \%)$. The overall
$(100 \%)$ of the respondent would support a smoking cessation at their place of employment but that number decreased when asked about supporting a smoking law banning smoking in public places $(72.6 \%)$ and areas involving children (58.6\%), such as a person's home and private vehicle $(54.4 \%$, $n=226$ ).

\section{Witnessed nurses performing health promotion activities:}

\section{Table no 1.8}

\begin{tabular}{|c|c|c|}
\hline \multirow[t]{2}{*}{ Please rate how often you witnessed nurses: } & Performed & $\begin{array}{l}\text { Did not } \\
\text { performed }\end{array}$ \\
\hline & $\%$ & $\%$ \\
\hline Involved in health policy change at their place of employment. & $88.2 \%$ & $11.8 \%$ \\
\hline Utilize the "5 rights" for medication administration. & $61.5 \%$ & $38.5 \%$ \\
\hline $\begin{array}{l}\text { Implement health policy changes within the community in } \\
\text { which they work. }\end{array}$ & $68.9 \%$ & $31.1 \%$ \\
\hline Initiate health education to clients without a physician's order. & $68.9 \%$ & $31.1 \%$ \\
\hline Accurately give injections. & $100.0 \%$ & $0.00 \%$ \\
\hline Assess client's preventive health care behaviours. & $80.7 \%$ & $19.3 \%$ \\
\hline $\begin{array}{l}\text { Examine the client's immediate environment for factors which } \\
\text { would adversely affect his/her health }\end{array}$ & $100.0 \%$ & $0.00 \%$ \\
\hline $\begin{array}{l}\text { Assess the community in which they live for factors which affect } \\
\text { health. }\end{array}$ & $88.1 \%$ & $11.9 \%$ \\
\hline Complete a physical assessment. & $100.0 \%$ & $0.00 \%$ \\
\hline $\begin{array}{l}\text { Increase their client's awareness on environmental factors } \\
\text { which would affect his/her health. }\end{array}$ & $100.0 \%$ & $0.00 \%$ \\
\hline Role model healthy behaviour. & $61.5 \%$ & $38.5 \%$ \\
\hline Assess client's health behaviours. & $40.8 \%$ & 59.3 \\
\hline Accurately take blood pressures. & $80.7 \%$ & $19.3 \%$ \\
\hline
\end{tabular}

Table no 1.8 indicates that health promoting activities performed by the nurses and observed by the majority participants (100\%) was giving accurate injection and Increase client's awareness on environmental factors which would affect his/her health. The overall results shows that nurses are performing health promoting activities as responded by the majority of participants. Only $(40.8 \%)$ of the participants witnessed nurses assessing clients' health behaviours and (61\%) participants responded that they witnessed nurses' role modelling healthy behaviours. 
Faculty role modelling health promoting behaviours:

\begin{tabular}{|c|c|c|}
\hline \multicolumn{3}{|l|}{ Table no 1.9} \\
\hline Nursing instructors performed health promoting behaviours. & Performed & $\begin{array}{l}\text { Did not } \\
\text { performed }\end{array}$ \\
\hline & $\%$ & $\%$ \\
\hline Non-smoking. & $88.1 \%$ & $11.9 \%$ \\
\hline Maintain ideal body weight. & $80.7 \%$ & $19.3 \%$ \\
\hline Engage in regular physical activity. & $47.4 \%$ & $52.6 \%$ \\
\hline Manage stress. & $39.3 \%$ & $60.7 \%$ \\
\hline Have healthy social interactions at work. & $80.7 \%$ & $19.3 \%$ \\
\hline Exhibit characteristics of good mental health. & $60.7 \%$ & $39.3 \%$ \\
\hline Eat healthy foods. & $73.3 \%$ & $26.7 \%$ \\
\hline $\begin{array}{l}\text { Be involved in local, state or national public health policy } \\
\text { change. }\end{array}$ & $11.9 \%$ & $88.1 \%$ \\
\hline Be involved in developing healthy environments. & $61.5 \%$ & $38.5 \%$ \\
\hline Be involved in influencing the economy to influence health. & $47.4 \%$ & $52.6 \%$ \\
\hline
\end{tabular}

Table 1.9 shows that nursing instructors were not always role modelling healthy behaviour, as perceived by nursing students. While nursing faculty are performing a lot of the health behaviours most of the time, some are still smoking (11.9\%), and not maintaining ideal body weight (19.3\%) $73.3 \%$ eats healthy foods, and only $47.4 \%$ engage in regular physical activity (see Table 4.7). The researcher clustered the individual behaviours, such as non-smoking, managing stress, maintaining ideal body weight, engaging in regular physical activity, exhibiting characteristics of good mental health, and having healthy social interactions at work, and then clustered the community activities of being involved in local, state or national public health policy change, developing healthy environments and influencing the economy to influence health. The individual activities were performed more frequently $(52.2 \%)$ by nursing instructors than the community activities $(32.5 \%)$.

\section{Chi-Square Test:}

Chi-Square test was used to compare the Post RN and BSN nursing students' perception of likelihood to perform health promoting activities upon the completion of program.

\section{Table 2}

\begin{tabular}{|c|c|c|c|c|c|}
\hline $\begin{array}{l}\text { Post RN vs BSN nursing students likelihood to } \\
\text { perform specific behaviours }\end{array}$ & $\begin{array}{l}\text { Post RN } \\
\mathrm{n}=46\end{array}$ & $\begin{array}{l}\mathrm{BSN} \\
\mathrm{n}=89\end{array}$ & $\begin{array}{l}\text { Chi- } \\
\text { Square }\end{array}$ & df & Sig $\mathrm{p}<$ \\
\hline Support changes for healthier selections & 34 & 66.2 & 3.376 & 1 & $* \mathrm{p}<.050$ \\
\hline $\begin{array}{l}\text { Changing unhealthy lifestyle behaviours for } \\
\text { clients. }\end{array}$ & 71.73 & 73.03 & 4.348 & 1 & $\mathrm{p}<.811$ \\
\hline $\begin{array}{l}\text { Offer child safety education to family members of } \\
\text { clients. }\end{array}$ & 82.6 & 83.15 & 4.136 & 1 & $* \mathrm{p}<.039$ \\
\hline $\begin{array}{l}\text { Talk to clients about recommendations for } \\
\text { physical activities. }\end{array}$ & 63.04 & 69.66 & 1.454 & 1 & $* \mathrm{p}<.016$ \\
\hline Talk to clients about nutritional requirements. & 67.4 & 53.93 & 3.501 & 1 & $* \mathrm{p}<.039$ \\
\hline
\end{tabular}

In comparing the post RN to BSN table no 5 shows that BSN students are more likely to performed health promoting activities upon the completion of study.

\section{Normality Tests:}

The obtained data was analysed for missing values and other typing errors to rectify the values. Data normality was examined through skewness and kurtosis. The score of nursing student perception were normally distributed and were in range from +1 to -1 showing the normality of data. 
Table 5: Summary of skewness and kurtosis results

\begin{tabular}{lll}
\hline & QNC & PP \\
\hline Skewness & -.417 & -.359 \\
S.E & .161 & .161 \\
Kurtosis & -.848 & .864 \\
S.E & .321 & .321 \\
\hline
\end{tabular}

\subsection{Discussion}

The purpose of the study is to assess nursing student perception regarding health promotion and health education. The data was collected from 135 nursing students currently enrolled in Post RN and BSN nursing programs at the Lahore School of Nursing, The University of Lahore. In compare to national league for nursing sample for this study was not similar demographically to national student nurses population (Godshall, Wilson, \& CHSE, 2016).

Participants in this study, who identified their gender, were 110 predominantly females $(81.5 \%$, $\mathrm{n}=135)$. This findings were similar $(\mathrm{p}<.08)$ to the national characteristics of student nurses graduating from basic nursing programs in which the majority are female $(88 \%)$.

The research included more students from the BSN $(65.9 \%, \mathrm{n}=135)$ and fewer students from the diploma $(34.1 \%, \mathrm{n}=135)$ than the national student nurse population. Statistically, the survey sample was not similar in terms of nursing programs to the national population $(\mathrm{p}<.02)$.

The first research question was: "How do nursing students define health". The majority of participants define health as recognized by world health organization that's been around and used by many professionals for many years. Students in nursing accepted that an individual's health is influenced by personal choices made by an individual, as well as by the society they live in. Students were more likely to agree that personal choices (88.9 percent, $n=135)$ impact an individual's wellbeing more than the society ( 88.9 percent, $n=135$ ) in which they live. From the findings of this study, this can be assumed that nursing students recognize that the environment affects an individual's health. This reinforces other study findings that indicated that nursing students recognized the importance of the social environment to health, but were unable to put into practice how they can influence the social environment to improve health. Nursing schools need to use their learning to allow students to improve their health by "combining academic and environmental support for behaviours and living conditions conducive to health" (Golden, McLeroy, Green, Earp, \& Lieberman, 2015).
The second research question asked was: "Can students in nursing describe the difference among the concept of health education and health promotion? The majority of participants respond that facilitating individuals with learning opportunities to improve health is health education and assisting individuals in learning skills needed to change health behaviours is health promotion. The overwhelming majority of participants respond that influencing economic conditions affect health concept related to both health promotion and health education and $38.5 \%$ participant's respond that influencing the physical environments which affect health is nor health education nor health promotion. It is evident from the results of this study that there is a lack of a universal understanding of health promotion and health education in nursing. This finding was similar to international studies conducted on health promotion and health education (whitehead, 2017), (Casey, 2017).

The third research question was: how many time the concept of health education and health promotion presented in nursing curriculum? At least 93 percent $(n=135)$ of the participants indicated that their nursing courses described health promotion and health education at least once. Approximately $96 \% \quad(n=135)$ of respondent reported hearing that health promotion and health education includes concepts such as involved with influencing physical environments, economic conditions, and making/changing strategies and social conditions that affect health.

The forth research question was: What health promoting behaviours is nursing faculty rolemodeling as perceived by their students? The results of this study revealed that the faculty of nursing always acts as reliable role models for student nurses. This research asked students about their experiences of nursing teachers practicing specific behaviours enhancing their own wellbeing and improving the community's health. According to nursing students, smoking, rarely engaging in physical activity and failing to maintain ideal body weight, some nursing instructors failed to act as role models for individual health behaviours. This study found that 11 percent of nursing teachers are smoking; while this figure is less than the 13 percent national smoking figures (CDC, 2018), progress towards a healthier lifestyle remains scope for improvement. Only $11 \% \quad(n=135)$ of the 
students nurse believe that nursing faculty engage in improvements to local, state or national public health policy. If nurse educators expect their students to be active in health promotion from an individual, as well as a community perspective, they need to act as role-models. A study conducted by Denehy (2013) indicated that nurses instructor need to be active participants in healthy behaviours in order to be reliable role models or advocates of health.

The fifth research question asked was: "What is the role of the nurse in implementing health promotion as perceived by nursing students?" to answer this question, The researcher asked questions about what students felt nurses should do and what students witness nurses doing and asked specific questions about what actions nursing student should conduct once they became nurses. All participants agreed that nurses had a role for individuals, groups and communities to encourage health promotion. The participants who answer "yes" nurses should talk about health and lifestyles routinely with their clients, $(27.4 \%)$ of the student nurses would not assess the client for high risk behaviours. Participants who said nurses should expand their health promotion efforts and provide health and lifestyle information to family members of their clients; $(33.1 \%)$ of them would not offer child safety education to family members of clients. Among the respondents who said that nurses are supposed to support healthier environments, all of the participants would be involved in helping pass state laws affecting health and $(67.4 \%)$ would be involved in supporting the building of physical environments.

In terms of health promotion, the participants in this study did not see nurses serving as role models. The results show that the majority of the participants $(68.9 \%)$ initiate health education to clients without a medical doctor's order. Only a small number of study participants witnessed the other listed health promotion activities.

Chi-square test was used to compare the likelihood of performing health promoting activities of post $\mathrm{RN}$ and BSN nursing students upon their completion of study. The results indicated that nursing students of both degrees will perform health promoting activities. These findings suggest that nursing student will be in involved in promoting health of individual rather than community and groups.

The data from this research established that the task of promoting health through a socio-ecological approach was either not being taught to nursing students, or not seeing themselves in. The answers of the students showed that they were told that health promotion was based more directly on modifying behaviours of individuals. Students had nursing instructors who played a role that modelled individual health promotion more than community health promotion and, in turn, nursing students were exposed to nurses who limited individual health promotion activities. This can happen because nurses usually do not see their position as health advocates by making policies, affecting the economy or improving the climate to have a positive impact on the community.

\subsection{Conclusion and Recommendation}

The findings indicated that only half of nursing students are informed that there is a difference between health promotion and health education by their nursing instructors. Although there were some signs that nursing students were introduced to the concept of health promotion as a socio-ecological strategy that integrates changes in the economy, policy, organization and climate. This socioecological approach was not viewed by the majority of student nurses as having a role modelling faculty or nurses. The expectations of student nurses about the nurse's role in promoting health have to do with modifying individual health habits as opposed to affecting the environment, social conditions, policies or anything beyond the patient. Curriculum improvements are not only required to integrate these accepted concepts of health promotion, but clinical practices are also needed to allow students to work in the expanded role of health promotion. Today's nursing students are not only limited in terms of health promotion in the clinical setting, but also in terms of health education. This research study elicited that student's nurses perceived health education as giving information regarding illness. Students of nursing need role models who incorporate individual healthy behaviours. All fields of nursing need to understand that if the broad socioecological approach is used, health is dramatically improved. Student nurses may not be able to see themselves fulfilling the expanded role of health promotion because they have no role models for nurse educators or nurses. Nurses need to be more involved in promoting the wellbeing of people, organizations, and societies by participating in the cultural, political, institutional, and environmental changes affecting health. Nurses and nursing educator need to understand that their patients ' wellbeing is influenced by social-ecological issues, not just the particular activities of the patient, regardless of the type of environment in which they operate.

\section{Limitation:}

This study has following limitation.

- This study was carried out in only one department of University of Lahore, so its 
findings cannot be generalized to overall populations.

- The results are based on self-reported data from participants, which limit the validity of the data.

- Simple size was small. Large sample will improve the accuracy of the results.

\section{Acknowledgement}

I would like to thank the following people who in many ways contributed to this piece of work. First and foremost, I would like to thank $\mathrm{Mr}$. Muhammad Afzal (The Principal of Lahore School of Nursing) who allowed me to do this study and guided me. I would thank to $\mathrm{Mr}$ Muhammad Husain for being my supervisor and for being the greatest inspiration for my work when I had no idea to perform a research work. I am indebted to him and I admire the way in which he explained very difficult concepts in very simple ways. I would also like to thank all the participants and my family member specially my Dad Mr Fazal Ghafoor (Principal Al-Hilal Public School) for giving me courage and guided me in every way of life. Their prayers made this study possible. It is a great pleasure to have all of these wonderful people in my life. I thank the management of University of Lahore.

\section{References}

1. Akhtar, S., Hussain, M., Afzal, M., \& Gilani, S. A. (2018). Barriers and Facilitators for Execution of Nursing Process among Nurses from Medical and Surgical Wards in a Public Hospital Lahore. International Journal of Social Sciences and Management, 5(3), 170186.

2. Association, A. N. (2014). Nursing's social policy statement: The essence of the profession: Nursesbooks. org.

3. Farmer, P., Meyer, D., Sroczynski, M., Close, L., Gorski, M. S., \& Wortock, J. (2017). RN to $\mathrm{BSN}$ at the Community College: A promising practice for nursing education transformation. Teaching and Learning in Nursing, 12(2), 103108.
4. Khalil, Iram Majeed, Afzal, M., \& Gilani, S. A. (2017). Assessment Of Nursing Student Perception Towards, Nursing Profession In Sir Ganga Ram Hospital And Ittefaq Hospital Trust Lahore, Pakistan.

5. Khan, N., \& Alam, B. (2015). Views of Nursing Students about Clinical Instructor behaviours That Affect the Development of Self-Confidence, Peshawar, KP, Pakistan. International Journal of Innovative Research and Development, 4(4).

6. Lewallen, T. C., Hunt, H., Potts-Datema, W., Zaza, S., \& Giles, W. (2015). The whole school, whole community, whole child model: A new approach for improving educational attainment and healthy development for students. Journal of School Health, 85(11), 729-739.

7. Maier, R. M., Díaz-Barriga, F., Field, J. A., Hopkins, J., Klein, B., \& Poulton, M. M. (2014). Socially responsible mining: the relationship between mining and poverty, human health and the environment. Reviews on environmental health, 29(1-2), 83-89.

8. Qidwai, W. (2016). Addressing healthcare challenges in Pakistan: Issues, possible remedies and way forward. Journal of Dow University of Health Sciences, 10(2).

9. Ramnanan, C. J., \& Pound, L. D. (2017). Advances in medical education and practice: student perceptions of the flipped classroom. Advances in medical education and practice, 8 , 63.

10. Shahzadi, A., Hussain, M., Afzal, M., \& Gilani, S. A. (2018). Determination the Level of Knowledge, Attitude, and Practices Regarding Household Waste Disposal among People in Rural Community of Lahore. International Journal of Social Sciences and Management, 5(3), 219-224.

11. Wilding, J. M. (2017). Perception: From sense to object: Routledge.

12. Woods, A., Cashin, A., \& Stockhausen, L. (2016). Communities of practice and the construction of the professional identities of nurse educators: A review of the literature. Nurse Education Today, 37, 164-169. 